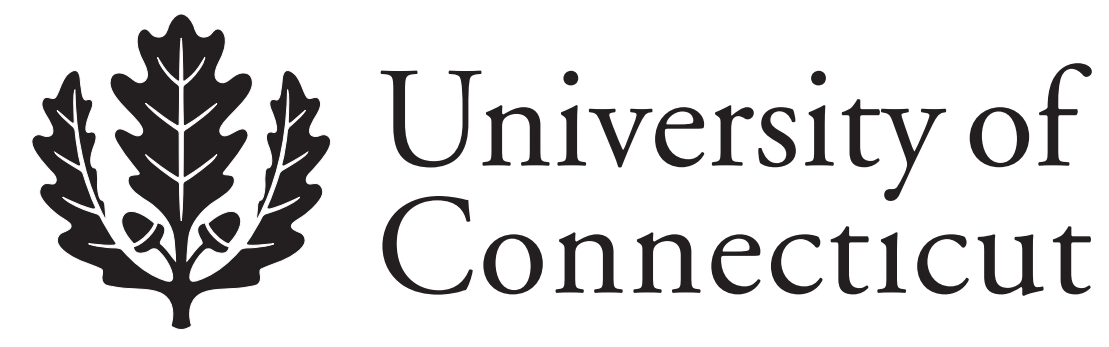

Department of Economics Working Paper Series

\title{
A Bargaining Model of Holdouts and Takings
}

Thomas Miceli

University of Connecticut

Kathleen Segerson

University of Connecticut

Working Paper 2006-22

June 2006

341 Mansfield Road, Unit 1063

Storrs, CT 06269-1063

Phone: (860) 486-3022

Fax: (860) 486-4463

http://www.econ.uconn.edu/

This working paper is indexed on RePEc, http://repec.org/ 


\begin{abstract}
The holdout problem is commonly cited as the justification for eminent domain, but the nature of the problem is not well understood. This paper models the holdout problem in a bargaining framework, where a developer seeks to acquire several parcels of land for a large-scale development. We show that in the absence of eminent domain, holdouts are inevitable, threatening costly delay. However, if the developer has the power to use eminent domain to acquire the land from holdouts, all sellers will bargain, thus avoiding delay. An offsetting cost is that owners may negotiate prices below their true value, possibly resulting in excessive transfer of land to the developer.
\end{abstract}

Journal of Economic Literature Classification: C78, K11, R14, R52

Keywords: Eminent domain, holdout problem, bargaining

We acknowledge the comments of participants at the Takings Conference at the University of California, Santa Barbara, May 12-13, 2006. 


\section{A Bargaining Model of Holdouts and Takings}

\section{Introduction}

The holdout problem is commonly (and properly) cited as the justification for forced sales of land under the government's power of eminent domain. ${ }^{1}$ The threat of holdouts arises when the government or a private developer attempts to assemble several contiguous parcels of land in order to complete a large-scale development project like a highway, railroad, or shopping center. In this setting, individual landowners, knowing that each of their parcels is essential for completion of the overall project, may seek prices in excess of their true valuations, thereby causing delay, increased costs, and possibly failure to complete the project at all.

Though the holdout problem has been much discussed by scholars, few have attempted to model it formally. ${ }^{2}$ As a result, its exact nature and the resulting inefficiency are unclear. Some have described it as a problem of monopoly, ${ }^{3}$ while others have characterized it in terms of transaction costs or breakdowns in bargaining. ${ }^{4}$ The monopoly argument seems to suggest that projects involving holdouts will be underprovided (due to the overpricing of land), while the bargaining cost approach tends to focus on delay as the primary source of inefficiency. ${ }^{5}$

In this paper, we adopt the latter perspective and examine the holdout problem in a bargaining framework. Specifically, we consider a government agency or private

\footnotetext{
${ }^{1}$ There is a large economic literature on eminent domain, beginning with the classic paper by Blume, Rubinfeld, and Shapiro (1984) (also see Hermalin (1995) and Nosal (2001)). However, most of this literature has focused on the impact of compensation on land use incentives and the taking decision by the government.

${ }^{2}$ Two exceptions are Strange (1995) and Menezes and Pitchford (2001).

${ }^{3}$ See, for example, Posner (2005, p. 55) and Knetsch and Borcherding (1979, p. 244).

${ }^{4}$ See Shavell (2005, p. 125) and Cooter and Ulen (1988, p. 193).

${ }^{5}$ On the latter point, see Fischel (1995, p. 68) and Hirsch (1999, p. 28).
} 
developer (henceforth, simply the developer) who needs to assemble several parcels of land for a large-scale project. The developer can negotiate individually, or jointly, with the owners and can do so in one of two periods. If, at the end of the second period, the developer has acquired all of the parcels, he can proceed with the project, but if not (i.e., if he has only acquired some or none of the parcels), he will scrap it. To capture the cost of delay, we assume that the gross value of the project is higher if it can be completed after the first period rather than after the second. We assume that individual sellers behave non-cooperatively in deciding when to come to the bargaining table, but that any sellers at the table in a given period engage in a Nash bargaining game with the developer to determine the prices of their individual parcels. ${ }^{6}$

In this setting, we show that holding out (i.e., waiting until the second period to bargain) is always a Nash equilibrium, and in some cases it is the only equilibrium. This is true even though completion of the project in the first period is a Pareto-superior outcome. The reason for this result is that each seller perceives that he would gain a bargaining advantage by waiting to sell in period two if all other sellers sell in period one.

Given the inefficiency associated with holdouts, we ask what will happen if the developer is given the power to use eminent domain in period two to take any parcels that he was not able to acquire consensually in period one. ${ }^{7}$ If compensation for takings is set at a property's market value (which we assume is less than its true value to the owner), we show that the unique equilibrium in the face of a takings threat is for all owners to sell in period one. Intuitively, owners sell in period one to avoid the loss from a taking in

\footnotetext{
${ }^{6}$ In this respect, the model closely resembles that developed by Menezes and Pitchford (2001) in a different context.

${ }^{7}$ We actually show that it is always optimal for the developer to try to bargain in period one, even if he has the right to use eminent domain in that period as well.
} 
period two. Thus, the mere threat of eminent domain is sufficient to overcome the holdout problem.

Although this outcome is potentially welfare-improving because it avoids the cost of delay, there is an offsetting cost owing to the fact that the takings threat may induce owners to sell at prices below their true reservation prices. As a result, developers may go ahead with inefficient projects - that is, projects whose gross value is less than the sum of the values of the individual parcels to their owners. This is possible in our model, even though eminent domain is never actually used, because of the effect of its threatened use on land prices.

We develop this argument as follows. Section 2 sets up the model. Section 3 describes the bargaining between the developer and landowners when there is no threat of a taking. Section 4 then shows how bargaining is affected when the developer has the power to use eminent domain to take any parcels that he is not able to acquire in a

consensual transaction. Section 5 examines the allocative cost of eminent domain, and Section 6 concludes.

\section{Setup of the Model}

Consider a developer who wishes to acquire two adjacent (and identical) parcels of land, designated A and B, for a development project. Let $V=$ gross value of the development if completed; $v=$ value of each parcel to its owner (the owner's reservation price); $m=$ market value of each parcel; also the value of a single parcel to the developer. We assume that 


$$
V>2 v
$$

reflecting the complementariness of the parcels when consolidated for development.

Given (1), it is efficient for the developer to acquire the parcels. We also assume,

however, that

$$
v>m,
$$

reflecting the fact that owners typically value their land in excess of its market value. This also implies that it is not efficient for the developer to acquire only one parcel.

We suppose that bargaining between the developer and the landowners can take place at two dates: $t=1$ (now), and $t=2$ (later). The developer can thus proceed with the development under any of the following scenarios: (a) he succeeds in buying both parcels now, (b) he buys one now and one later, (c) and he buys both later. However, if he is unable to acquire both parcels by $t=2$, we assume that he abandons the project altogether, resulting in a return of zero if he has acquired neither parcel, and $m$ if he has acquired only one.

Note that scenarios (b) and (c) differ from (a) in that completion of the project is delayed. We assume that this imposes a cost on the developer equal to $\delta>0$. However, we also assume that

$$
V-\delta>2 v
$$

implying that it is still efficient to complete the development at this date. The cost of delay is the sole cost associated with the holdout problem in the current model. ${ }^{8}$ Finally, we assume that all payoffs are realized at $t=2$, and there is no discounting.

\footnotetext{
${ }^{8}$ This reflects Cohen's (1991, p. 354) argument that buyers and sellers ultimately recognize their joint interests in completing a sale. Another interpretation of $\delta$ is that it is the transaction costs the developer must incur in order to strike a bargain with holdouts. Regardless of the interpretation, one would expect $\delta$
} 


\section{Bargaining between the Developer and Landowners when there is no Threat of Eminent Domain}

We consider a two-stage game in which sellers first make a non-cooperative choice of when to bargain with the developer (now or later). Then, in each of the two periods, any sellers at the bargaining table engage in Nash bargaining with the developer. We proceed in reverse sequence by first describing the outcome of the bargaining in each period.

\section{A. Bargaining}

Consider first the case where period two has arrived and the developer has acquired neither of the parcels. That is, both owners were period-one holdouts. Since (3) implies there is still a surplus to be divided among the three parties, and there is no possible bargaining in the future, both sellers have an interest in engaging in bargaining now. ${ }^{9}$ If the developer acquires both parcels, his net return is

$$
V-\delta-P_{2}{ }^{\mathrm{A}}-P_{2}{ }^{\mathrm{B}},
$$

where $P_{2}{ }^{\mathrm{A}}$ and $P_{2}{ }^{\mathrm{B}}$ are the prices obtained by owners $\mathrm{A}$ and $\mathrm{B}$ in period $2 .{ }^{10}$ As noted, the developer's threat point is zero since failure to acquire both parcels will result in the project's being scrapped. As for sellers, their return from a sale is simply the price, and their threat points are $v$. Using the Nash bargaining solution applied to a three-way bargain (Osborne and Rubinstein, 1990, p. 23), we obtain the prices by solving:

$$
\max _{P_{2}^{A}, P_{2}^{B}}\left(V-\delta-P_{2}{ }^{\mathrm{A}}-P_{2}{ }^{\mathrm{B}}\right)\left(P_{2}{ }^{\mathrm{A}}-v\right)\left(P_{2}{ }^{\mathrm{B}}-v\right) .
$$

to be increasing in the number of parcels that must be assembled, and also possibly in the magnitude of the surplus generated by assembly.

${ }^{9}$ In contrast, condition (2) implies that a unilateral sale would never be profitable in $t=2$.

${ }^{10}$ Henceforth, superscripts denote parcels and subscripts denote periods. 
Since the sellers are identical, each sells for

$$
\hat{P}_{2}=\frac{V-\delta+v}{3}
$$

The resulting net return to the developer, found by setting $P_{2}{ }^{\mathrm{A}}=P_{2}{ }^{\mathrm{B}}=\hat{P}_{2}$ in (4), is

$$
\frac{V-\delta-2 v}{3}
$$

which is positive given (3).

Consider next the case where the developer succeeded in acquiring parcel $\mathrm{A}$ in period 1 for a price $\bar{P}_{1}^{\mathrm{A}}$, and now seeks to buy parcel B in period two for a price $P_{2}{ }^{\mathrm{B}}$. If he succeeds his net return is again given by (4), but his threat point is now $m-\bar{P}_{1}$ A . The situation for the seller is the same as before. Thus, $P_{2}{ }^{\mathrm{B}}$ solves

$$
\max _{P_{2}^{B}}\left[\left(V-\delta-\bar{P}_{1}^{\mathrm{A}}-P_{2}{ }^{\mathrm{B}}\right)-\left(m-\bar{P}_{1}^{\mathrm{A}}\right)\right]\left(P_{2}{ }^{\mathrm{B}}-v\right) .
$$

The result is

$$
P_{2}^{*}=\frac{V+v-\delta-m}{2}
$$

(Note that this price is independent of the period one price.) Comparison of (6) and (9) shows that $P_{2} *>\hat{P}_{2}$ given (2) and (3). Thus, it is better for a seller to be a lone holdout compared to the case where both holdout and sell in period two.

Now move back to period one. There are three possibilities here: (a) both sellers bargain (and sell), (b) one sells and one holds out, and (c) both holdout. We have already seen that case (c) results in sale by both sellers in period two for $\hat{P}_{2}$. Thus, we need only consider (a) and (b). In case (a), both sellers bargain. If both sell, the developer's net 
return is $V-P_{1}{ }^{\mathrm{A}}-P_{1}{ }^{\mathrm{B}},{ }^{11}$ and each seller receives the sale price. As for the threat points, note that a failure to reach a bargain in period one still allows the parties to bargain in period two. Thus, the threat points for all three parties are the net returns from that bargain as derived above (specifically, the price in (6) for each seller and the return in (7) for the developer). Bringing all of this together, we can determine the period-one prices from a three-way bargain as the solution to

$$
\max _{P_{1}^{A}, P_{1}^{B}}\left[\left(V-P_{1}^{A}-P_{1}^{B}\right)-\left(\frac{V-\delta-2 v}{3}\right)\right]\left[P_{1}^{A}-\left(\frac{V-\delta+v}{3}\right)\right]\left[P_{1}^{B}-\left(\frac{V-\delta+v}{3}\right)\right] .
$$

Symmetry again implies that both sellers sell for the same price:

$$
\hat{P}_{1}=\frac{V+v}{3}
$$

Comparison of (6) and (11) shows that $\hat{P}_{1}>\hat{P}_{2}$. That is, sellers would prefer to sell jointly in period one rather than period two, owing to the larger surplus available to be divided in period one. Further, comparison of (9) and (11) shows that $P_{2} * \frac{\geq}{<} \hat{P}_{1}$. Thus, a seller may or may not prefer being the lone holdout in period one compared to the case where both sell in one. The reason for the ambiguity here is the cost of delay, $\delta$, which favors a sale by both in period one. Thus, the larger is $\delta$ the more likely it is that $P_{2} *<\hat{P}_{1} \cdot 12$

The final case is where owner A sells in period one while owner B holds out. Both the developer and the willing seller anticipate that the holdout will sell in period two for $P_{2}^{*}$ (assuming that the period-one sale occurs), and the threat points, as above, are the

\footnotetext{
${ }^{11}$ Note that there is no cost of delay in this case.

12 The specific condition for $P_{2} *$ to be larger is $2 \delta<V-\delta+v-3 m$, where the right-hand side is positive by (2) and (3). Thus, $P_{2} *$ will definitely be larger if $\delta=0$.
} 
returns from a joint sale in period two. Thus, $P_{1}{ }^{\mathrm{A}}$ in the current case is determined by the solution to

$$
\max _{P_{1}^{A}}\left[\left(V-\delta-P_{1}^{A}-P_{2}^{*}\right)-\left(\frac{V-\delta-2 v}{3}\right)\right]\left[P_{1}^{A}-\left(\frac{V-\delta+v}{3}\right)\right],
$$

and the result is

$$
P_{1}^{*}=\frac{V+v-\delta+m}{4}
$$

Using our previous results, we can show that $P_{2} *>P_{1} *$, and $\hat{P}_{1}>\hat{P}_{2}>P_{1} *$. Thus, being the lone seller in period one is clearly the worst possible outcome.

\section{B. Equilibrium Behavior of Sellers}

Now that we have derived the equilibrium prices under the assumption of cooperative bargaining among those at the bargaining table, we turn to the choices of individual sellers regarding when to come to the bargaining table and when to holdout. As noted above, the sellers make this choice non-cooperatively.

In deciding when to come to the bargaining table, each seller has two possible strategies: bargain, or holdout. The analysis in the previous section determined the prices that would result from each possible combination of these strategies, and they are shown in Table 1. (Note that because we assumed that any period-one holdouts would bargain in period two, there is no separate decision in that period. Thus, the strategy "holdout" means holdout now and bargain in period two.)

[Table 1 here] 
The nature of the equilibria depends on relationship between $P_{2} *$ and $\hat{P}_{1}$, which we showed above is ambiguous. Thus, there are two possibilities. First, when $P_{2} *>\hat{P}_{1}$, there is a unique Nash equilibrium wherein both sellers holdout. In this case, the individual gain from being the lone holdout dominates the joint benefits from a periodone sale by both sellers. Thus, holding out is a dominant strategy for both sellers. Alternatively, when $P_{2} *<\hat{P}_{1}$, there are two pure strategy Nash equilibria: (bargain, bargain) and (holdout, holdout). In this case, the best strategy depends on what each seller thinks the other will do. Although both sellers are better off if they jointly bargain ( since $\hat{P}_{1}>\hat{P}_{2}$ ), each wants to guard against the possibility of being the lone seller in period one.

In terms of efficiency, the net gain is $V-2 v$ when both sellers agree to sell in period one, and $V-\delta-2 v$ when both holdout in period one and then sell in period two. Thus, although development in either period is preferred to the status quo, there is a social cost associated with delay. Despite this cost, the results in this section show that there is no way to guarantee that a holdout problem will not occur, and in some cases, it is the only equilibrium.

\section{Bargaining in the Shadow of Eminent Domain}

This section asks whether the threat of a taking by the developer can help to alleviate the risk of a holdout problem. ${ }^{13}$ We assume that the developer first seeks to

\footnotetext{
${ }^{13}$ We have not distinguished between public and private projects, so our model does not shed any light on the "public use" question - that is, the question of whether private developers should ever have the power of eminent domain to overcome holdouts, or whether its use should be limited to government projects. The Supreme Court recently ruled that under certain circumstances, private developers should have the power
} 
negotiate a consensual sale with both sellers in period one (as above), but that he has the right to use eminent domain in period two to take any properties that he was unable to acquire in period one. (We show below that it is always optimal for the developer to try to negotiate a sale before resorting to eminent domain anyway.) If the developer takes a property, he has to pay the owner its market value, $m$, and he also incurs a transaction/litigation cost, $\tau$, per property taken. We assume sellers incur no transaction costs when their land is taken, but they do incur a loss given $m<v$.

As above, we begin in period two by considering the case where neither property was acquired in period one (i.e., both sellers held out). In this case, the developer will take both properties provided that

$$
V-\delta-2(m+\tau) \geq 0
$$

Note that a sufficient condition for (14) to hold, given (3), is $m+\tau \leq v$. Similarly, if the developer was only able to acquire one property in period one for a price $P_{1}$, he will take the second in period two provided that

$$
V-\delta-(m+\tau)-P_{1} \geq m-P_{1}
$$

or

$$
V-\delta-2 m-\tau \geq 0
$$

which is satisfied given (14).

Assuming that (14) holds, the threat to use eminent domain in period two is credible. Thus, we turn to the bargaining between the developer and the sellers in period one in the shadow of this threat. Consider first the case where both sellers bargain. In

(see Kelo v. City of New London (2005)), but the issue remains controversial. See Epstein (1985, Chapter 12), Merrill (1986), and Fischel (1995, pp. 71-75). 
this case, the threat point for the sellers is $m$, while the threat point for the developer is the left-hand side of (14). The prices therefore solve

$$
\max _{P_{1}^{A}, P_{1}^{B}} \mid\left(V-P_{1}^{A}-P_{1}^{B}\right)-\left(V-\delta-2(m+\tau) \mathfrak{k}\left(P_{1}^{A}-m\right)\left(P_{1}^{B}-m\right),\right.
$$

which yields

$$
\hat{P}_{1}=m+\frac{2 \tau+\delta}{3}
$$

Sellers are thus able to extract a price in excess of their market value because, by selling in period one, they save the developer the cost of delay plus the transaction costs of using eminent domain. Nevertheless, there is no guarantee that (17) is larger than the sellers' reservation price, $v$. This reflects the developer's credible threat to take the land for $m$ in period two. (We return to this point in the next section.) Finally, note that the developer is better off seeking to bargain in period one rather than resorting to eminent domain immediately since his surplus from doing to (the term in square brackets in (16)) turns out to be $(\delta+2 \tau) / 3$ in equilibrium, which is clearly positive.

Consider next the case where only seller A bargains in period one while seller B holds out. The threat points are the same as in (16), but in this case, the developer's return if he succeeds in buying parcel $\mathrm{A}$ is $V-\delta-P_{1}{ }^{\mathrm{A}}-(m+\tau)$ since he will have to take parcel $\mathrm{B}$ by eminent domain in period two. The sale price for parcel $\mathrm{A}, P_{1}^{\mathrm{A}}$, is therefore determined by

$$
\max _{P_{1}^{A}}\left[\left(V-\delta-P_{1}{ }^{\mathrm{A}}-(m+\tau)\right)-(V-\delta-2(m+\tau))\right]\left(P_{1}{ }^{\mathrm{A}}-m\right),
$$

and the resulting price is

$$
P_{1}^{*}=m+\frac{\tau}{2}
$$


Comparison of (17) and (19) shows that $\hat{P}_{1}>P_{1}^{*}>m$. Thus, from the perspective of individual sellers, it is best if both sell in period one, next best to be the lone seller in period one, and worst to be a holdout.

Given these results, we now reconsider the equilibrium decisions of sellers in the face of eminent domain. The payoff matrix is shown in Table 2, where $\hat{P}_{1}$ and $P_{1} *$ are now given by (17) and (19). The unique Nash equilibrium in this case is for both sellers to bargain. Thus, the threat of eminent domain does in fact succeed in eliminating the holdout problem. (Note that because eminent domain is never actually used in equilibrium, the litigation costs are never incurred.)

\section{[Table 2 here]}

\section{The Cost of Eminent Domain}

The preceding analysis has shown that the economic benefit of eminent domain is avoidance of the holdout problem. In this sense, it improves efficiency by saving the cost of delay. In this section, however, we note an offsetting cost of eminent domain that arises from the possibility that owners, when faced with the threat of a taking, may sell their properties for less than their opportunity costs. First, note that the condition for this underpricing to occur is that the expression in (17) is less than $v$, or

$$
v-m>\frac{2 \tau+\delta}{3}
$$

which is more likely to hold the larger is the owner's "subjective value," $v-m$, and the smaller are the developer's litigation costs and costs of delay. ${ }^{14}$

\footnotetext{
${ }^{14}$ It is worth noting that the left- and right-hand sides of (20) may not be independent. Specifically, as a landowner's subjective value, $v-m$, grows, he is likely to fight harder to avoid a taking, in which case the
} 
When (20) holds, the threat of eminent domain redistributes the gains from development in favor of the developer compared to a world in which sellers have the right to refuse any offer. While this does not represent a loss in efficiency when condition (1) holds (i.e., given that the project promises a net benefit), it does entail a loss in welfare to the extent that considerations of fairness and/or respect for private property rights matter to society. ${ }^{15}$

In addition, however, the possibility that owners will agree to sell their properties for less than their reservation prices may entail a loss in efficiency due to the risk of excessive takings. The problem is that there may be no way to ensure that the targeted land is more valuable to the developer than to the owners absent the owners' right to refuse to sell. In ordinary market transactions, an owners' right of refusal guarantees that any transfer of property is value-enhancing in the sense that the buyer values the property more than the seller. In contrast, when the developer has the power of eminent domain, we have shown that owners may consent to sell for prices below their true reservation price for fear that their land will be taken for an even smaller amount of compensation later. This will result in inefficient projects going forward if $2 v>V>2 \hat{P}_{1}$, or if $v>\hat{P}_{1}$, which is the same as condition (20).

The crux of the problem, of course, is that courts have interpreted the "just compensation" provision of the Fifth Amendment to require market-value compensation,

\footnotetext{
litigation cost of using eminent domain, $\tau$, will tend to increase as well. Based on this logic, Merrill (1986, p. 101) and Fischel (1995, p. 74) have argued that eminent domain will tend to be "self-limiting," especially in cases where the cost of holdouts (as captured by $\delta$ on the right-hand side of (20)) is small.

${ }^{15}$ This reflects Epstein's (1985, Chapter 12) concern about the allocation of the surplus from a taking as between the beneficiaries of the taking and those whose land is taken.
} 
the justification being that they cannot observe the true value of the land to the owner. ${ }^{16}$ This illustrates a fundamental trade-off associated with eminent domain. On one hand, there is the risk of costly delay in the production of large-scale projects due to the holdout problem, but on the other there is the possibility of overinvestment in such projects due to the underpricing of properties in the face of a takings threat. ${ }^{17}$ The optimal scope of eminent domain must balance these offsetting factors.

\section{Conclusion}

This paper has examined the impact of eminent domain on the bargaining between a developer and landowners when the potential for holdouts exists. The key conclusion is that the threatened use of eminent domain overcomes the holdout problem, thereby promising a potential gain in efficiency. An offsetting cost, however, is that by removing landowners' right to refuse a sale, there is a risk of excessive transfer of land to the developer. This suggests that use of eminent domain should be limited to large-scale projects in which the threat of holdouts is significant.

\footnotetext{
${ }^{16}$ See Knetsch and Borcherding (1979), Epstein (1985, pp. 174-175), and Fischel (1995, pp. 207-209). In practice, the difference between $v$ and $m$ is likely to be larger the longer the owner of the land (or his ancestors) has occupied the property. As Oliver Wendell Holmes (1897, p. 477) colorfully observed, "A thing which you have enjoyed and used as your own for a long time, whether property or an opinion, takes root in your being and cannot be torn away without your resenting the act and trying to defend yourself..." ${ }^{17}$ This same trade-off arises whenever a "liability rule" (a forced sale) is substituted for a "property rule" (a market transfer). See generally Calabresi and Melamed (1972) and Kaplow and Shavell (1996).
} 


\section{References}

Blume, Lawrence, Daniel Rubinfeld, and Perry Shapiro (1984) "The Taking of Land: When Should Compensation be Paid?" Quarterly Journal of Economics 99: 71-92.

Calabresi, Guido and A. Douglas Melamed (1972) "Property Rules, Liability Rules, and Inalienability: One View of the Cathedral," Harvard Law Review 85: 1089-1128.

Cohen, Lloyd (1991) "Holdouts and Free Riders," Journal of Legal Studies 20: 351-362.

Cooter, Robert and Thomas Ulen (1988) Law and Economics, Glenview, Ill.: Scott, Foresman and Co.

Epstein, Richard (1985) Takings: Private Property and the Power of Eminent Domain, Cambridge, MA: Harvard Univ. Press.

Fischel, William (1995) Regulatory Takings: Law, Economics, and Politics, Cambridge, MA: Harbard Univ. Press.

Hermalin, Benjamin (1995) "An Economic Analysis of Takings," Journal of Law, Economics \& Organization 11: 64-86.

Hirsch, Werner (1999) Law and Economics, $2^{\text {nd }}$ Edition, Boston, MA: Academic Press.

Holmes, Oliver Wendell (1897) “The Path of the Law," Harvard Law Review 10: 461478.

Kaplow, Louis and Steven Shavell (1996) "Property Rules and Liability Rules," Harvard Law Review 109: 713-790.

Knetsch, Jack and Thomas Borcherding (1979) "Expropriation of Private Property and the Basis for Compensation," University of Toronto Law Journal 29: 237-252.

Menezes, Flavio and Rohan Pitchford (2001) "Chasing Patents," Working Paper, Australian National University.

Merrill, Thomas (1986) "The Economics of Public Use," Cornell Law Review 72: 61116.

Nosal, Ed (2001) "The Taking of Land: Market Value Compensation Should be Paid," Journal of Public Economics 82: 431-443.

Posner, Richard (2003) Economic Analysis of Law, $6^{\text {th }}$ Edition, New York: Aspen Law \& Business. 
Shavell, Steven (2005) Foundations of Economic Analysis of Law, Cambridge, MA: Harvard Univ. Press.

Strange, William (1995) "Information, Holdouts, and Land Assembly," Journal of Urban Economics 38: 317-332. 


\section{Seller 2}

\begin{tabular}{|c|c|c|c|}
\hline \multirow{3}{*}{ Seller 1} & & Bargain & Holdout \\
\hline & Bargain & $\hat{P}_{1}, \hat{P}_{1}$ & $P_{1} *, P_{2} *$ \\
\hline & Holdout & $P_{2}^{*}, P_{1}^{*}$ & $\hat{P}_{2}, \hat{P}_{2}$ \\
\hline
\end{tabular}

Table 1: Payoff matrix for sellers' choice of when to bargain.

\section{Seller 2}

\begin{tabular}{|c|c|c|c|}
\hline \multirow{3}{*}{ Seller 1} & & Bargain & Holdout \\
\hline & Bargain & $\hat{P}_{1}, \hat{P}_{1}$ & $P_{1}^{*}, m$ \\
\hline & Holdout & $m, P_{1}^{*}$ & $m, m$ \\
\hline
\end{tabular}

Table 2: Payoff matrix for sellers in face of eminent domain. 